\title{
No differences in central corneal thickness between open-angle and pseudoexfoliation glaucoma patients
}

This article was published in the following Dove Press journal:

Clinical Ophthalmology

19 April 2017

Number of times this article has been viewed

\author{
Marcelo Ayala' \\ Johanna Karlsson² \\ 'Eye Department, Skaraborg Hospital, \\ Skövde, Sahlgrenska Academy, \\ Gothenburg University and Karolinska \\ Institute, ${ }^{2}$ Faculty of Medicine, Örebro \\ University, Örebro, Sweden
}

Introduction: Measurements of intraocular pressure (IOP) with Goldmann applanation tonometry are affected by central corneal thickness (CCT), as thinner corneas underestimate and thicker corneas overestimate the true IOP value. The literature is controversial regarding CCT values in patients with primary open-angle glaucoma (POAG) and exfoliation glaucoma (XFG). The aim of this study was to evaluate CCT in patients with XFG and POAG.

Methods: CCT was evaluated with optical coherence tomography (OCT). All participants who were previously diagnosed with either POAG or XFG underwent ophthalmological examinations. Contact lens users and patients with corneal diseases were excluded.

Results: Totally, 145 patients were enrolled in this study. The mean CCT was $535 \pm 30.4 \mu \mathrm{m}$ in patients with POAG and was $536 \pm 33.7 \mu \mathrm{m}$ in patients with XFG. The result was not statistically significant $(P=0.98)$. The mean age for all participants was $73.8 \pm 7.7$ years. The study included totally 61 women and 84 men. The two groups were similar in their demographic data, and mean deviation was the only parameter that differed statistically when comparing POAG with $\mathrm{XFG}(P=0.02)$.

Conclusion: Our data indicate that patients with XFG do not have thinner corneas than those with POAG, and therefore, CCT can not explain why they progress differently.

Keywords: primary open-angle glaucoma, exfoliative glaucoma, central corneal thickness, optical coherence tomography

\section{Introduction}

Glaucoma is the second leading cause of blindness worldwide. ${ }^{1}$ It consists of a heterogeneous group of diseases, all characterized by optic-nerve damage causing irreversible visual field loss and vision impairment, which slowly can progress to blindness if not treated. ${ }^{2}$ Open-angle glaucoma (OAG) is the most common form of glaucoma in the Western world. ${ }^{1}$

The etiology of OAG is still unknown, but genetic and environmental risk factors are thought to be involved., ${ }^{3,4}$ The intraocular pressure (IOP) is considered to be the most important risk factor for developing glaucoma. ${ }^{5}$ IOP is an important factor for monitoring glaucoma treatment and determining glaucoma severity, ${ }^{6}$ and it is also the only treatable risk factor. Other risk factors are, for example, older age, thin central cornea, ethnicity, family history and pseudoexfoliation., ${ }^{5,-9}$

There are different types of OAG, of which the most common type is primary open-angle glaucoma (POAG). ${ }^{2}$ Exfoliative glaucoma (XFG) is a secondary form of OAG with faster progression and worse prognosis than POAG. ${ }^{10,11} \mathrm{XFG}$ is characterized by accumulation of abnormal fibers in the anterior segment of the eye, causing
Correspondence: Marcelo Ayala Eye Department, Skaraborg Hospital, 54185 Skövde, Sweden

Tel +46500 431000

Fax +46500432179

Email marcelo.ayala@vgregion.se 
disrupted drainage of aqueous humor and elevation of IOP. ${ }^{11}$ The progression of XFG is correlated with the level of IOP, and patients with XFG more often require not only medical treatment but also laser and surgery to lower the IOP. ${ }^{12}$ By lowering IOP in patients with $\mathrm{OAG}$, further progression of this condition can be prevented or delayed. ${ }^{13-15}$

The "gold standard" method to measure IOP is Goldmann applanation tonometry (GAT). It is well known that measurements of IOP with GAT are affected by central corneal thickness (CCT), as thinner corneas underestimate and thicker corneas overestimate the true IOP value. ${ }^{16-18}$ Moreover, thinner CCT has been shown to be a predictor for the development of POAG in patients with ocular hypertension. ${ }^{5}$ Patients with thinner corneas are more likely to have visual field progression ${ }^{19}$ and a worse visual field defect. ${ }^{20}$

The CCT differs in different populations ${ }^{21}$ and in different types of glaucoma. ${ }^{22}$ Genetic factors have been shown to be of major importance in CCT. ${ }^{23}$ It has been shown that AfroAmericans have a thinner CCT than other populations. ${ }^{21,24,25}$ However, the literature is controversial regarding the differences in corneal thickness in patients with POAG and XFG. Some studies have shown eyes with XFG to have thinner CCT compared to POAG and/or normal eyes, ${ }^{21,22,26-29}$ while other studies have found thicker CCT in XFG compared to POAG and/or normal eyes. ${ }^{30-34}$

The aim of this study was to evaluate central corneal thickness in patients with XFG and POAG.

\section{Methods}

\section{Study protocol}

A comprehensive medical and ocular history was obtained from patients. Ophthalmological examination was performed before including these patients in the study. Visual acuity, IOP measurements, optic-nerve status, gonioscopy, Humphrey visual fields (HFA, 24-2) and presence or absence of exfoliation were recorded. Visual acuity was recorded using Snellen's chart. IOP was measured using a Goldmann applanation tonometer. Three measurements were done and the average value was calculated. Then, the pupils were dilated and exfoliation was checked and recorded as present or absent. Afterward, the optic-nerve status was evaluated using a 90-D lens, and hence, stereo photographs were taken. Previous eye surgery was also registered.

Glaucoma was defined, following the European guidelines for glaucoma, as the presence of at least two repeatable Humphrey visual fields showing glaucoma damage in patients, using the software 24-2 and the optic nerve showing typical glaucoma damage. ${ }^{35}$ Demographic data, such as gender, age, ocular history, visual field and number of antiglaucomatous medical methods, were also recorded. Inclusion criteria were patients who were previously diagnosed with POAG or XFG according to their medical records. Diagnosis was based on optic disc appearance and visual field damage. Subjects were excluded if they were contact lens users or had any corneal disease.

POAG was defined as the condition, as above, without the presence of exfoliation in dilated pupil. XFG was defined as open angle, concomitant with the presence of exfoliation material, a grayish-white material, observed at the anterior lens capsule and/or at the pupillary border with dilated pupil. Patients who were operated for cataract were diagnosed with exfoliation before cataract operation.

CCT was measured by optical coherence tomography (OCT, 3D OCT-2000 and 3D OCT-1000; Topcon Corporation, Tokyo, Japan) using the anterior segment imaging protocol. Only images of good quality were recorded (>60 signal strength). CCT was measured by two examiners, a senior consultant ophthalmologist (M.A.) and a medical student (J.K.). The measurements were done during the daytime, from 8 am to $5 \mathrm{pm}$. Both eyes were measured in all patients once. If patients had bilateral glaucoma, one eye was later randomly selected to be included in the statistical analysis.

\section{Statistical methods}

Statistical analysis was performed with SSPS (SPSS, Chicago, IL, USA). First, the data were tested for normality using the Kolmogrov-Smirnov test. Then, the data were tested for equality of variance using Levene's test. Student's $t$-test was used to compare CCT values and demographic data between patients with POAG and XFG. For comparison of gender between the two groups, a chi-squared test was used. Averages \pm standard deviations (SDs) were used to report data. A $P$-value of 0.05 or less was considered to be statistically significant. Sample size was estimated to be 63 individuals in each group with a significance level of 0.05 and power of $90 \%$.

\section{Ethical considerations}

Ethical approval was received from the Institutional Review Board (Ethical approval number: 717-13), Gothenburg University, Gothenburg, Sweden. The study followed the tenets of the Declaration of Helsinki. A written informed consent was obtained from all patients who participated in this study, and their medical records were controlled, before they were included into this study. 


\section{Results}

Totally, 145 patients were included in this study between December 2013 and December 2016. Of them, 66 patients were diagnosed with POAG and 79 with XFG. All patients were born in Scandinavia. The mean age for all participants was $73.8 \pm 7.7$ years, and the age range was $52-93$ years. There were totally 61 women and 84 men included in this report. The demographic properties of two glaucoma groups are presented in Table 1.

The two groups were similar in their demographic data, and mean deviation (MD) was the only parameter that differed statistically when comparing POAG with XFG $(P=0.02)$.

Regarding CCT, the data are found to be normally distributed (Kolmogrov-Smirnov; $P=0.20$ ), and the variances between the groups are shown to be equal (Levene's test; $P=0.36$ ). The mean CCT was $535 \pm 30.4 \mu \mathrm{m}$ in patients with POAG and was $536 \pm 33.7 \mu \mathrm{m}$ in patients with XFG. The result was not statistically significant ( $t$-test; $P=0.98$ ). The mean was adjusted for confounding factors. The adjusted mean was $469.40 \mu \mathrm{m}$ in POAG patients and was $480.04 \mu \mathrm{m}$ in XFG patients.

Data from four patients were excluded due to difficulties in recording of the measurements $(n=3)$ and failure of the equipment $(\mathrm{n}=1)$.

\section{Discussion}

Central corneal thickness is a well-known factor affecting IOP readings with GAT. It was earlier shown by Goldmann and Schmid $^{36}$ and Ehlers et al ${ }^{37}$ that IOP readings with GAT could give falsely elevated or decreased IOP readings depending on the corneal thickness. Ehlers et $\mathrm{al}^{37}$ reported that accurate measurements only were given at a central corneal thickness of $520 \mu \mathrm{m}$. They found that for each $10 \mu \mathrm{m}$ it varies from $520 \mu \mathrm{m}$, a correction of $0.7 \mathrm{~mm} \mathrm{Hg}$

Table I Demographic data of the study groups

\begin{tabular}{llll}
\hline Characteristics & POAG & XFG & P-value \\
\hline Age (SD), years & $74.2(9.0)$ & $73.4(6.3)$ & $0.57^{\mathrm{a}}$ \\
Sex (male/female) & $40 / 26$ & $44 / 35$ & $0.13^{\mathrm{b}}$ \\
IOP (SD), mmHg & $16.8(5.0)$ & $16.8(3.2)$ & $0.97^{\mathrm{a}}$ \\
VFI (SD), \% & $81.8(23.5)$ & $73.7(26.2)$ & $0.09^{\mathrm{a}}$ \\
MD (SD), dB & $-7.3(7.6)$ & $-10.4(8.1)$ & $0.02^{\mathrm{a}}$ \\
PSD (SD), dB & $5.2(3.8)$ & $6.0(3.5)$ & $0.27^{\mathrm{a}}$ \\
Trabeculectomy & $8(12.1 \%)$ & $8(10.3 \%)$ & $0.71^{\mathrm{b}}$ \\
Cataract operation & $20(30.3 \%)$ & $21(26.9 \%)$ & $0.72^{\mathrm{b}}$ \\
\hline
\end{tabular}

Note: ${ }^{2}$ Two-tailed $t$-test; ${ }^{b} \mathrm{Chi}$-square test.

Abbreviations: POAG, primary open-angle glaucoma; XFG, exfoliation glaucoma; $\mathrm{SD}$, standard deviation; IOP, intraocular pressure; $\mathrm{VFI}$, visual field index; MD, mean deviation; PSD, pattern standard deviation. is needed. Other reports have later revealed average correction to be lower, namely $0.18-0.23 \mathrm{mmHg},{ }^{38} 0.19 \mathrm{mmHg}^{39}$ and $0.5 \mathrm{mmHg}$ per $10 \mu \mathrm{m} .{ }^{40}$

CCT values among normal individuals without glaucoma vary and are normally found to be $540 \pm 30 \mu \mathrm{m} .40-42$ The literature is controversial regarding CCT in patients with POAG and XFG and how they correlate with each other and with normal individuals without glaucoma. In our report, no statistical significant differences in CCT could be detected between these glaucoma types. These results are in concordance with other reports. Studies by Tolesa and Gessesse, ${ }^{30}$ Ventura et al, ${ }^{31}$ Shah et $\mathrm{al}^{32}$ and Ozkok et al ${ }^{33}$ did not find any significant difference in corneal thickness between XFG and POAG. Tolesa and Gessesse ${ }^{30}$ found, in their multiethnic report, thicker CCT in patients with POAG $(520 \pm 38.95 \mu \mathrm{m})$ compared to XFG $(507 \pm 35)$, but these results were not significant. In the report by Ventura et al, ${ }^{31}$ the mean CCT was $515 \pm 35 \mu \mathrm{m}$ in eyes with POAG and was $507 \pm 25 \mu \mathrm{m}$ in XFG. Shah et al ${ }^{32}$ reported mean CCT to be $530.7 \mu \mathrm{m}$ in XFG and $550.1 \mu \mathrm{m}$ in POAG, and Ozkok et $\mathrm{al}^{33} 546 \pm 34.9 \mu \mathrm{m}$ vs $550 \pm 25 \mu \mathrm{m}$. In this study, we found the mean CCT to be $536 \pm 33.7 \mu \mathrm{m}$ in XFG eyes and $535 \pm 30.4 \mu \mathrm{m}$ in POAG eyes. Previous reports cited in this article ${ }^{6,18,21,22,26-33,43}$ have reported mean CCT in patients with XFG to be between $493-546 \mu \mathrm{m}$ and $507-556 \mu \mathrm{m}$. Our results accord with previous studies.

Reports by Kitsos et al, ${ }^{26}$ Bechmann et al, ${ }^{28}$ Gorezis et al ${ }^{22}$ and Kniested ${ }^{29}$ found CCT to be significantly lower in XFG compared to POAG. They had included only $32,24,50$ and 12 XFG patients, respectively. No evidence was found in the literature about published studies comparing XFG to POAG with the same number of XFG patients than the ones included in this report. Furthermore, according to our estimation of sample size, 63 individuals in each group with significance of 0.05 and power of $90 \%$ were needed. Often, estimation of sample size has not been included in previous studies, which may contribute to explain why some studies found a difference and some not in CCT between POAG and XFG. Another possible explanation about the small number of XFG included in previous studies may be that XFG is quite common in Scandinavian countries. It might be difficult to recruit enough number of participants in studies performed in other countries, and therefore, leading to too small sample size of exfoliation patients.

Disagreement between studies could be explained by different techniques used to measure CCT. Currently, CCT can be measured by ultrasound pachymetry (USP), optical low-coherence reflectometry (OLCR), anterior segment 
optical coherence tomography and Scheimpflug camera. Comparison in CCT between XFG and POAG has mostly been done using USP. ${ }^{26,30,32,33}$ Bechmann et $\mathrm{al}^{28}$ used OCT, Ventura et $\mathrm{al}^{31}$ used OLCR and Gorezis et $\mathrm{al}^{22}$ used a pecular microscope. USP is currently the gold standard for measuring corneal thickness, but it has some limitations. The examiner must place the probe at the exact same position at the center of the cornea, otherwise a different CCT value will be obtained. ${ }^{44}$ It also requires topical anesthesia before measurement can be accomplished, which can affect cornea and the results. ${ }^{45}$ OCT has the advantages of being a noninvasive, noncontact technique, and therefore, no topical anesthesia is needed to perform the measurement. It is also less affected by the examiner's knowledge and experience, and has high degree of repeatability and reproducibility. ${ }^{46}$ Additionally, incorrect placement of a probe cannot bias OCT results. ${ }^{47}$

Previous reports have shown that OCT gives lower CCT readings compared to ultrasound. ${ }^{47-49}$ The opposite, overestimation with OCT compared to USP has also been reported. ${ }^{50,51}$ Wells et $\mathrm{l}^{48}$ compared optical pachymetry, OCT and ultrasound, and found that these devices are not interchangeable in clinical practice. Garcia-Medina et $\mathrm{al}^{49}$ compared Fourier-Domain OCT with USP in 80 patients with POAG and found a significant difference between the mean CCT. However, they indicated that this difference should not be clinically significant in IOP estimation. There is also a report by Adibelli et al, ${ }^{51}$ showing a significant difference between OCT and USP in 26 POAG patients, where mean CCT was higher with OCT compared to USP. Comparison by Ayala and Strandås ${ }^{50}$ between OCT and USP did not show any difference between these two devices. However, this might be a reason for different outcomes when measuring CCT worldwide. As reported by Wells et al, ${ }^{48} \mathrm{CCT}$ can vary up to $30 \mu \mathrm{m}$ when using different instruments.

There is a lack of information in the literature about how interchangeable the devices are concerning XFG patients. Maybe, the exfoliation material at the endothelium disturbs the measurement with OCT, creating a false thicker cornea and, therefore, we did not find any difference between these two glaucoma types. Further studies are needed to investigate the issue. However, in our study patients suffering from POAG and XFG were measured with the same technique (OCT) minimizing the risk of bias. Regarding demographic data, our two groups were very similar. Only mean deviation differed statistically. This is in concordance with The Early Manifest Glaucoma Trial, showing a faster progression rates in $\mathrm{MD}$ in patients with XFG than in POAG. ${ }^{52}$
The study has several limitations. The examiners were not blinded to condition the patient had, and therefore there are some risks for bias. The fact that two different examiners performed the measurements can induce certain bias to the study. However, a recent study by the same author has shown that there are no differences between the examiners measuring with OCT. ${ }^{50}$ There is also risk of selection bias as the recruitment of the patients was performed at an eye clinic. Variation in measurements due to lack of patients' cooperation may also be a limitation. During measurements with OCT, the patient should be able to focus her or his gaze on something during the measurement. This was difficult only for a few patients because of the inability to understand instructions owing to very poor hearing or dementia. However, the same difficulties would be present in the both glaucoma types included. Another possible bias in the study was that patients were recruited directly from the clinic, and patients were in different stages of their illnesses as same as using different amount of eye drops.

\section{Conclusion}

Our data indicate that patients with XFG do not have thinner corneas than those with POAG, and therefore CCT can not explain why they progress differently.

\section{Acknowledgment}

The authors thank the Skaraborg Hospital Research Center for support.

\section{Disclosure}

The authors report no conflicts of interest in this work.

\section{References}

1. Quigley HA, Broman AT. The number of people with glaucoma worldwide in 2010 and 2020. Br J Ophthalmol. 2006;90(3):262-267.

2. Weinreb RN, Khaw PT. Primary open-angle glaucoma. Lancet. 2004; 363(9422):1711-1720.

3. Yilmaz SG, Palamar M, Onay H, et al. LOXL1 gene analysis in Turkish patients with exfoliation glaucoma. Int Ophthalmol. 2016; 36(5):629-635

4. Pasquale LR, Kang JH, Wiggs JL. Prospects for gene-environment interactions in exfoliation syndrome. J Glaucoma. 2014;23(8 Suppl 1): S64-S67.

5. Gordon MO, Beiser JA, Brandt JD, et al. The Ocular Hypertension Treatment Study: baseline factors that predict the onset of primary openangle glaucoma. Arch Ophthalmol. 2002;120(6):714-720; discussion 829-830.

6. Herndon LW, Weizer JS, Stinnett SS. Central corneal thickness as a risk factor for advanced glaucoma damage. Arch Ophthalmol. 2004; 122(1):17-21.

7. Allingham RR, Loftsdottir M, Gottfredsdottir MS, et al. Pseudoexfoliation syndrome in Icelandic families. Br J Ophthalmol. 2001;85(6): 702-707. 
8. Le A, Mukesh BN, McCarty CA, Taylor HR. Risk factors associated with the incidence of open-angle glaucoma: the visual impairment project. Invest Ophthalmol Vis Sci. 2003;44(9):3783-3789.

9. Wolfs RC, Klaver CC, Ramrattan RS, van Duijn CM, Hofman A, de Jong PT. Genetic risk of primary open-angle glaucoma. Populationbased familial aggregation study. Arch Ophthalmol. 1998;116(12): 1640-1645.

10. Hyman L, Heijl A, Leske MC, Bengtsson B, Yang Z; Early Manifest Glaucoma Trial Group. Natural history of intraocular pressure in the early manifest glaucoma trial: a 6-year follow-up. Arch Ophthalmol. 2010;128(5):601-607.

11. Ritch R, Schlötzer-Schrehardt U. Exfoliation syndrome. Surv Ophthalmol. 2001;45(4):265-315.

12. Konstas AG, Stewart WC, Stroman GA, Sine CS. Clinical presentation and initial treatment patterns in patients with exfoliation glaucoma versus primary open-angle glaucoma. Ophthalmic Surg Lasers. 1997; 28(2):111-117.

13. Heijl A, Leske MC, Bengtsson B, Hyman L, Bengtsson B, Hussein M, et al; Early Manifest Glaucoma Trial Group. Reduction of intraocular pressure and glaucoma progression: results from the Early Manifest Glaucoma Trial. Arch Ophthalmol. 2002;120(10):1268-1279.

14. Kass MA, Heuer DK, Higginbotham EJ, et al. The Ocular Hypertension Treatment Study: a randomized trial determines that topical ocular hypotensive medication delays or prevents the onset of primary openangle glaucoma. Arch Ophthalmol. 2002;120(6):701-713; discussion 829-830.

15. Leske MC, Heijl A, Hyman L, Bengtsson B, Dong L, Yang Z; EMGT Group. Predictors of long-term progression in the early manifest glaucoma trial. Ophthalmology. 2007;114(11):1965-1972.

16. Stodtmeister R. Applanation tonometry and correction according to corneal thickness. Acta Ophthalmol Scand. 1998;76(3):319-324.

17. Lee M, Ahn J. Effects of central corneal stromal thickness and epithelial thickness on intraocular pressure using Goldmann applanation and non-contact tonometers. PLoS One. 2016;11(3):e0151868.

18. Yagci R, Eksioglu U, Midillioglu I, Yalvac I, Altiparmak E, Duman S. Central corneal thickness in primary open angle glaucoma, pseudoexfoliative glaucoma, ocular hypertension, and normal population. Eur J Ophthalmol. 2005;15(3):324-328.

19. Kim JW, Chen PP. Central corneal pachymetry and visual field progression in patients with open-angle glaucoma. Ophthalmology. 2004; 111(11):2126-2132.

20. Iester M, Telani S, Frezzotti P, et al; Italian Glaucoma Register. Differences in central corneal thickness between the paired eyes and the severity of the glaucomatous damage. Eye (Lond). 2012;26(11):1424-1430.

21. Aghaian E, Choe JE, Lin S, Stamper RL. Central corneal thickness of Caucasians, Chinese, Hispanics, Filipinos, African Americans, and Japanese in a glaucoma clinic. Ophthalmology. 2004;111(12): 2211-2219.

22. Gorezis S, Christos G, Stefaniotou M, Moustaklis K, Skyrlas A, Kitsos G. Comparative results of central corneal thickness measurements in primary open-angle glaucoma, pseudoexfoliation glaucoma, and ocular hypertension. Ophthalmic Surg Lasers Imaging. 2008;39(1):17-21.

23. Toh T, Liew SH, MacKinnon JR, et al. Central corneal thickness is highly heritable: the twin eye studies. Invest Ophthalmol Vis Sci. 2005; 46(10):3718-3722.

24. La Rosa FA, Gross RL, Orengo-Nania S. Central corneal thickness of Caucasians and African Americans in glaucomatous and nonglaucomatous populations. Arch Ophthalmol. 2001;119(1):23-27.

25. Shimmyo M, Ross AJ, Moy A, Mostafavi R. Intraocular pressure, Goldmann applanation tension, corneal thickness, and corneal curvature in Caucasians, Asians, Hispanics, and African Americans. Am J Ophthalmol. 2003;136(4):603-613.

26. Kitsos G, Gartzios C, Asproudis I, Bagli E. Central corneal thickness in subjects with glaucoma and in normal individuals (with or without pseudoexfoliation syndrome). Clin Ophthalmol. 2009;3:537-542.

27. Yazgan S, Celik U, Alagöz N, Taş M. Corneal biomechanical comparison of pseudoexfoliation syndrome, pseudoexfoliative glaucoma and healthy subjects. Curr Eye Res. 2015;40(5):470-475.
28. Bechmann M, Thiel MJ, Roesen B, Ullrich S, Ulbig MW, Ludwig K Central corneal thickness determined with optical coherence tomography in various types of glaucoma. Br J Ophthalmol. 2000;84(11):1233-1237.

29. Kniestedt C, Lin S, Choe J, et al. Correlation between intraocular pressure, central corneal thickness, stage of glaucoma, and demographic patient data: prospective analysis of biophysical parameters in tertiary glaucoma practice populations. J Glaucoma. 2006;15(2):91-97.

30. Tolesa K, Gessesse GW. Central corneal thickness in newly diagnosed glaucoma patients in South West Ethiopia: a cross-sectional study. BMC Ophthalmol. 2016;16(1):152.

31. Ventura AC, Böhnke M, Mojon DS. Central corneal thickness measurements in patients with normal tension glaucoma, primary open angle glaucoma, pseudoexfoliation glaucoma, or ocular hypertension. $\mathrm{Br} \mathrm{J}$ Ophthalmol. 2001;85(7):792-795.

32. Shah S, Chatterjee A, Mathai M, et al. Relationship between corneal thickness and measured intraocular pressure in a general ophthalmology clinic. Ophthalmology. 1999;106(11):2154-2160.

33. Ozkok A, Tamcelik N, Ozdamar A, Sarici AM, Cicik E. Corneal viscoelastic differences between pseudoexfoliative glaucoma and primary open-angle glaucoma. J Glaucoma. 2013;22(9):740-745.

34. Hepsen IF, Yağci R, Keskin U. Corneal curvature and central corneal thickness in eyes with pseudoexfoliation syndrome. Can J Ophthalmol. 2007;42(5):677-680.

35. European Glaucoma Society. Terminology and Guidelines for Glaucoma. 3rd ed. Savona, Italy: Dogma; 2008.

36. Goldmann H, Schmid T. [Applanation tonometry]. Ophthalmologica. 1957;134(4):221-242. German [with English abstract].

37. Ehlers N, Bramsen T, Sperling S. Applanation tonometry and central corneal thickness. Acta Ophthalmol (Copenh). 1975;53(1):34-43.

38. Whitacre MM, Stein RA, Hassanein K. The effect of corneal thickness on applanation tonometry. Am J Ophthalmol. 1993;115(5):592-596.

39. Wolfs RC, Klaver CC, Vingerling JR, Grobbee DE, Hofman A, de Jong PT. Distribution of central corneal thickness and its association with intraocular pressure: The Rotterdam Study. Am J Ophthalmol. 1997; 123(6):767-772.

40. Doughty MJ, Zaman ML. Human corneal thickness and its impact on intraocular pressure measures: a review and meta-analysis approach. Surv Ophthalmol. 2000;44(5):367-408.

41. Rahman ML, Bunce C, Healey PR, et al. Commingling analyses of central corneal thickness and adjusted intraocular pressure in an older Australian population. Invest Ophthalmol Vis Sci. 2010;51(5):2512-2518.

42. Eysteinsson T, Jonasson F, Sasaki H, et al; Reykjavik Eye Study Group. Central corneal thickness, radius of the corneal curvature and intraocular pressure in normal subjects using non-contact techniques: Reykjavik Eye Study. Acta Ophthalmol Scand. 2002;80(1):11-15.

43. Inoue $\mathrm{K}$, Okugawa $\mathrm{K}$, Oshika $\mathrm{T}$, Amano S. Morphological study of corneal endothelium and corneal thickness in pseudoexfoliation syndrome. Jpn J Ophthalmol. 2003;47(3):235-239.

44. Kuerten D, Plange N, Koch EC, Koutsonas A, Walter P, Fuest M. Central corneal thickness determination in corneal edema using ultrasound pachymetry, a Scheimpflug camera, and anterior segment OCT. Graefes Arch Clin Exp Ophthalmol. 2015;253(7):1105-1109.

45. Mukhopadhyay DR, North RV, Hamilton-Maxwell KE. Effect of a proparacaine $0.50 \%$-sodium fluorescein $0.25 \%$ mix and contact ultrasound pachymetry on central and midperipheral corneal thickness measured by noncontact optical pachymetry. J Cataract Refract Surg. 2011;37(5):907-913.

46. Muscat S, McKay N, Parks S, Kemp E, Keating D. Repeatability and reproducibility of corneal thickness measurements by optical coherence tomography. Invest Ophthalmol Vis Sci. 2002;43(6):1791-1795.

47. Bechmann M, Thiel MJ, Neubauer AS, et al. Central corneal thickness measurement with a retinal optical coherence tomography device versus standard ultrasonic pachymetry. Cornea. 2001;20(1):50-54.

48. Wells M, Wu N, Kokkinakis J, Sutton G. Correlation of central corneal thickness measurements using Topcon TRK-1P, Zeiss Visante AS-OCT and DGH Pachmate 55 handheld ultrasonic pachymeter. Clin Exp Optom. 2013;96(4):385-387. 
49. Garcia-Medina JJ, Garcia-Medina M, Garcia-Maturana C, ZanonMoreno V, Pons-Vazquez S, Pinazo-Duran MD. Comparative study of central corneal thickness using Fourier-domain optical coherence tomography versus ultrasound pachymetry in primary open-angle glaucoma. Cornea. 2013;32(1):9-13.

50. Ayala M, Strandås R. Accuracy of optical coherence tomography (OCT) in pachymetry for glaucoma patients. BMC Ophthalmol. 2015; 15:124.
51. Adibelli FM, Oğuz H, Göncü T, Yilmaz OF, Yuksekyayla F. A comparison of central corneal thicknesses measured with two different methods in cases of primary open-angle glaucoma. Semin Ophthalmol. 2016:1-3.

52. Heijl A, Bengtsson B, Hyman L, Leske MC; Early Manifest Glaucoma Trial Group. Natural history of open-angle glaucoma. Ophthalmology. 2009;116(12):2271-2276.

\section{Publish your work in this journal}

Clinical Ophthalmology is an international, peer-reviewed journal covering all subspecialties within ophthalmology. Key topics include: Optometry; Visual science; Pharmacology and drug therapy in eye diseases; Basic Sciences; Primary and Secondary eye care; Patient Safety and Quality of Care Improvements. This journal is indexed on

\section{Dovepress}

PubMed Central and CAS, and is the official journal of The Society of Clinical Ophthalmology (SCO). The manuscript management system is completely online and includes a very quick and fair peer-review system, which is all easy to use. Visit http://www.dovepress.com/ testimonials.php to read real quotes from published authors. 